\title{
Incidence of Atrial Fibrillation in Acute St-Elevation Myocardial Infarction
}

\author{
Azka Ishtiaq ${ }^{1}$, Ayesha Rasool ${ }^{2}$, Bakhtawar Khalil ${ }^{3}$ \\ 1,2,3. House Officer Nishtar Hospital, Multan \\ Correspounding Author:ayesharasool@gmail.com
}

\begin{abstract}
:
Objective: of our study was to evaluate the incidence of acute fibrillation developing in the context of acute myocardial infarction population. Methodology: This cross sectional study was carried out in department Cardiology Nishtar Hospital, Multan under supervision of senior cardiologists. Patients who were presented with acute myocardial infarction selected for study, duration April 2018 to February 2019. Data was entered and analyzed by using SPSS software, mean and SD representation was done for continuous data like age and frequency (percentages \%) representation were done for categorical variables like gender, hypertension, DM, onset of old AF and new AF. chi square test was applied to see association between variables. $P$ value less than or equal to 0.05 was considered as significant. Results: A total of 214 patients were enrolled in this study. There was association between new onset of AF and age $(p=0.000)$. Old AF found in $7.9 \%(n=17)$ in patients. The main outcome of this study was new outset AF, in our study, it was found in $18.7 \%(n=40)$ patients. Conclusion: New onset of atrial fibrillation is a common type of Arrhythmia which is highly associated with ST segment elevation mayocardial infarction or acute mayocardial infarction.
\end{abstract}

Keywords: Acute myocardial infarction, atrial fibrillation, prognosis, ST segment elevation.

DOI: $10.7176 / \mathrm{JMPB} / 52-13$

\section{Introduction:}

Most common arrhythmia of acute ST segment elevation is atrial fibrillation; it is also frequent in acute coronary syndrome $^{1}$. It is reported in previous literature that incidence of atrial fibrillation in AMI increased $13.3 \%$ in last few years. In setting G of AMI atrial fibrillation have bad impact with slow clinical outcomes and poor prognosis ${ }^{2}$. Outcomes of its treatment and prognosis can increased with better perfusion strategies which include use of angiotension enzyme inhibitors and PCI, statins, modern antithrombotic treatment and angiotensionreceptors blockers in acute myocardial infarction patients ${ }^{3,4}$.

Along with advance management of AMI there is a need of treatment of its new acute phase attacks, it could be with lifestyle modifications or dietary changes ${ }^{5}$. Predictors of new onset should inhibit. In $12 \%$ of AF cases can be encountered with thrombolytic agents or PCI. About $4.5 \%$ cases which are treated with primary PCI have arrhythmia in pre hospital time ${ }^{6}$. Incidence of AF found to be doubled when observed with long term implantable event loop in comparison with ECG monitoring 7 . Patients of AF with acute phase of AMI faces more badly condition when they are in their older age, hemodynamicaly unstable and increase in comorbidities ${ }^{8}$.

In a previous trial which was conducted on four thrombolytic regimens it was reported that patients of AF were mostly female of older age having high heart rate and low blood pressure, some other risk factors include previous history of myocardial infarction, hypertension ${ }^{9}$, compromised heart, low ejection fraction, coronary artery disease and triple vessel disease. Incidence of atrial fibrillation can be treated with beta blockers and aspirin, its advance management include digoxin, anti arrhythmics and warfarin ${ }^{10}$. Local evidences of AF in acute MI are much deficient, we decided to conduct this study, which will provide basis for fut.ure research on this very import subject

\section{Methodology}

This cross sectional study was carried out department Cardiology Nishtar Hospital, Multan under supervision of senior cardiologists Patients who were presented with acute myocardial infarction selected for study, duration April 2018 to February 2019, age more than 18 years and raised troponin level were included in the study. Sampling technique used for this study was non probability consecutive. Sample size was taken after using CI of $95 \%$, power $80 \%$ and onset of new atrial fibrillation of (p) $8 \%$. Patients were also evaluated for prolonged ischemic signs and ST segment depression or elevation on ECG. Patients who were send to another institution for any procedure which is more than 24 hours prolonged, who did not give consent for inclusion in the study were excluded from the study. Patients detailed history for socioeconomic status, previous illness or comorbid disease and previous hospital admission and treatment was obtained. Blood samples were drawn taking all aseptic measures. Our main outcome variable is new onset of AF in time duration of AMI admission in hospital. It was considered as AF when it was recorded on 12 leads ECG for more than 30 seconds. Patient's biomarker, detailed history points, and new onset of AF were recorded.

Data was entered and analyzed by using SPSS software, mean and SD representation was done for continuous data like age and frequency (percentages \%) representation were done for categorical variables like gender, 
hypertension, DM, onset of old AF and new AF. chi square test was applied to see association between variables. $P$ value less than or equal to 0.05 was considered as significant.

Results:

A total of 214 patients were enrolled in this study, both genders. Gender distribution showed there were $57.9 \%(n=124)$ males and $42.1 \%(n=90)$ females. The mean age of the patients was $63.24 \pm 3.03$ years. Hypertension noted in $70.1 \%(\mathrm{n}=150)$ patients. While, DM was found in $76.2 \%(\mathrm{n}=163)$ patients. There was association between new outset AF and age $(p=0.000)$. Old AF found in $7.9 \%(n=17)$ in patients. The main outcome of this study was new outset AF, in our study, it was found in $18.7 \%(n=40)$ patients. (Table. 1-3).

Table-1: Demographic characteristics

\begin{tabular}{|c|c|c|}
\hline Variable & Frequency & Percentage \\
\hline Gender & $\mathrm{M}=124, \mathrm{~F}=90$ & $\mathrm{M}=57.9 \%, \mathrm{~F}=42.1 \%$ \\
\hline Hypertension & 150 & 70.1 \\
\hline DM & 163 & 76.2 \\
\hline Age (years) & \multicolumn{2}{|c|}{$63.24 \pm 3.03$} \\
\hline
\end{tabular}

Table-2: Onset of old and new Atrial Fibrilation

\begin{tabular}{|c|c|c|}
\hline Variable & Frequency & Percentage \% \\
\hline Old AF & 17 & $7.9 \%$ \\
\hline New outset AF & 40 & $18.7 \%$ \\
\hline
\end{tabular}

Table-3: Association of new outset AF with effect modifiers

\begin{tabular}{|c|c|c|c|c|c|}
\hline \multicolumn{2}{|c|}{ Effect Modifiers } & \multicolumn{2}{|c|}{ New outset AF } & \multirow[t]{2}{*}{ Total } & \multirow[t]{2}{*}{ P-value } \\
\hline & & Yes & No & & \\
\hline \multirow[t]{2}{*}{ Gender } & Male & 20 & 104 & 124 & \multirow[t]{3}{*}{0.259} \\
\hline & Female & 20 & 70 & 90 & \\
\hline \multicolumn{2}{|c|}{ Total } & 40 & 174 & 214 & \\
\hline \multirow[t]{2}{*}{ Stratified Age } & 38-50 Years & 4 & 94 & 98 & \multirow[t]{3}{*}{0.000} \\
\hline & 51-82 Years & 36 & 80 & 116 & \\
\hline & & 40 & 174 & 214 & \\
\hline \multirow{3}{*}{ Hypertension } & Yes & & & & \multirow{4}{*}{0.129} \\
\hline & & 32 & 118 & 150 & \\
\hline & No & 8 & 56 & 64 & \\
\hline & & 40 & 174 & 214 & \\
\hline \multirow[t]{2}{*}{ DM } & Yes & 32 & 131 & 163 & \multirow{3}{*}{0.528} \\
\hline & No & 8 & 43 & 51 & \\
\hline & & 40 & 174 & 214 & \\
\hline \multirow[t]{3}{*}{ Old AF } & Yes & 5 & 12 & 17 & \multirow{3}{*}{0.237} \\
\hline & No & 35 & 162 & 197 & \\
\hline & Total & 40 & 174 & 214 & \\
\hline
\end{tabular}




\section{Discussion:}

It was seen in previous literature that onset of new AF is associated with reflex automatic heart rate control especially in those patients who were diagnosed with acute myocardial infarction. In our main outcome of our study was new outset AF and it was found in $18.7 \%$ of patients. This may $b$ due to hemodynamic changes which are observed in most of STEMI patients.

In a study conducted by Lehto $\mathrm{M}$ et $\mathrm{al}^{11}$ reported $12 \%$ atrial fibrillation and among them $7.2 \%$ patients were those who develop new onset after acute mayocardial infarction. Mostly AF was observed after AMI which leads to heart failure and may be death. This study is comparable with our study but onset of new AF was less than ours. This incidence may be varying from area to area of living style.

In another study conducted by Køber L et a ${ }^{12}$ on this topic in 2006 and reported $37 \%$ incidence of current AF in previous AMI patients which is a high ratio as compared to almost all previous studies conducted on this topic. In another study by Jons $\mathrm{C}$ et $\mathrm{al}^{13}$ reported that incidence of new onset of AF is after MI is high about $16 \%$ was reported, he also claims that this incidence rate is higher in first two month after MI and then decreases with time. Cerit $\mathrm{L}^{14}$ et al conducted a study in 2017 and reported that AF is highly associated with AMI and in cases of MI arrhythmias are common, among them AF is most common type of arrhythmia. In a study conducted by Lopes $\mathrm{RD}$ et $\mathrm{al}^{15}$ and reported incidence of new onset of $\mathrm{AF}$ after MI 6.3\%. It is not a too much high percentage and also similar ratio was reported. This study is also comparable with our study.

In our study we observed that incidence of new onset of AF in MI patients is also associated with age, with passage of time risk of this incidence also increases. In a study conducted by Vukmirović $\mathrm{M}$ et $\mathrm{al}^{16}$ reported $6 \%$ incidence of AF after AMI and also reported that new onset of AF is associated with age. Arrhythmias are common in older age. Pedersen OD et ${ }^{17}$ al also reported that atrial flutter and fibrillation is common in after AMI in older ages.

In a study conducted by Pizzetti F et ${ }^{18}$ al reported $7.8 \%$ incidence of AF after AMI and reported that AMI patients shows worse prognosis after AF. Anoter study by Crenshaw BS et al ${ }^{19}$ also reported similar findings. This study is comparable with our study. In other studies similar findings were reported and it is a calibrated fact that new onset of AF after AMI is common arrhythmia and found to be fatal and high incidence of mortality associated with $\mathrm{it}^{20}$.

\section{Conclusion:}

New onset of atrial fibrillation is a common type of Arrhythmia which is highly associated with ST segment elevation mayocardial infarction or acute mayocardial infarction.

\section{References:}

1. Patel NJ, Patel A, Agnihotri K, et al. Prognostic impact of atrial fibrillation on clinical outcomes of acute coronary syndromes, heart failure and chronic kidney disease. World J Cardiol. 2015;7(7):397-403.

2. Bang CN, Gislason GH, Greve AM, et al. New-Onset Atrial Fibrillation is Associated With Cardiovascular Events Leading to Death in a First Time Myocardial Infarction Population of 89703 Patients With Long-Term Follow-Up: A Nationwide Study. J Am Heart Assoc: 2014;3(1):e000382.

3. Bas HA, Aksoy F, Icli A, Varol E, Dogan A, Erdogan D. The association of plasma oxidative status and inflammation with the development of atrial fibrillation in patients presenting with ST elevation myocardial infarction. Scand J Clin Lab Invest. 2017;77(2):77-82.

4. Jovin IS, Shah RM, Patel DB, Rao SV, Baklanov DV, Moussa I. Outcomes in Patients Undergoing Primary Percutaneous Coronary Intervention for ST-Segment Elevation Myocardial Infarction Via Radial Access Anticoagulated With Bivalirudin Versus Heparin: A Report From the National Cardiovascular Data Registry. JACC Cardiovasc Interv. 2017;10(11):1102-1111.

5. Distelmaier K, Maurer G, Goliasch G. Blood count in new onset atrial fibrillation after acute myocardial infarction - A hypothesis generating study. Indian J Med Res. 2014;139(4):579-584.

6. Poster session 6: Saturday 6 December 2014, 08:30-12:30Location: Poster area. Eur Heart J Cardiovasc Imaging. 2014;15(Suppl 2):ii235-ii264.

7. Giglioli C, Minelli M, Chiostri M, Landi D, Romano SM, Balzi D. Prognostic impact of atrial fibrillation occurrence in patients with non-ST-elevation acute coronary syndromes: is dysrhythmia duration a parameter to focus on?. Intern Emerg Med. 2014;9(5):521-528.

8. Carvalho A, F, Berk M, Hyphantis T, N, McIntyre R, S, The Integrative Management of TreatmentResistant Depression: A Comprehensive Review and Perspectives. Psychother Psychosom 2014;83:7088 .

9. Potpara TS, Lip GY. A Brief History of 'Lone' Atrial Fibrillation: From 'A Peculiar Pulse Irregularity' to a Modern Public Health Concern. Curr Pharm Des. 2015;21(5):679-696.

10. Kundu A, O'Day K, Shaikh AY. Relation of Atrial Fibrillation in Acute Myocardial Infarction to InHospital Complications and Early Hospital Readmission. Ame J cardiol. 2016;117(8):1213-1218. 
11. Lehto M, Snapinn S, Dickstein K, Swedberg K, Nieminen MS; OPTIMAAL investigators. Prognostic risk of atrial fibrillation in acute myocardial infarction complicated by left ventricular dys- function: the OPTIMAAL experience. Eur Heart J. 2005;26:350-6.

12. Køber L, Swedberg K, McMurray JJV. Previously known and newly diagnosed atrial fibrillation: A major risk indicator after a myocardial infarction complicated by heart failure or left ventricu- lar dysfunction. Eur J Heart Fail. 2006:8;591-8.

13. Jons C, Jacobsen UG, Joergensen RM. Cardiac Arrhythmias and Risk Stratification after Acute Myocardial Infarction (CARISMA) Study Group. The incidence and prognostic signifi- cance of newonset atrial fibrillation in patients with acute myocar- dial infarction and left ventricular systolic dysfunction: a CARISMA substudy. Heart Rhythm. 2011;8:342-8.

14. Cerit L. Recurrent acute myocardial infarction and atrial fibrillation. J Geriatr Cardiol. 2017;14(2):153154.

15. Lopes RD, Elliott LE, White HD. Antithrombotic therapy and outcomes of patients with atrial fibrillation following primary per- cutaneous coronary intervention: results from the APEX-AMI trial. Eur Heart J. 2009;30:2019-28.

16. Vukmirović M. Predictors and outcomes of new-onset atrial fibrillation in patients with acute myocardial infarction. Vojnosanit Pregl. 2017;74(8):742-748.

17. Pedersen OD, Abildstrøm SZ, Ottesen MM. TRACE Study Investigators. Increased risk of sudden and non-sudden cardiovas- cular death in patients with atrial fibrillation/flutter following acute myocardial infarction. Eur Heart J. 2006;27:290-5.

18. Pizzetti F , Turazza FM , Franzosi MG; GISSI-3 Investiga- tors. Incidence and prognostic significance of atrial fibrillation in acute myocardial infarction: the GISSI-3 data. Heart. 2001;86:527-32.

19. Crenshaw BS, Ward SR, Granger CB, Stebbins AL, Topol EJ, Califf RM. Atrial fibrillation in the setting of acute myocardial in- farction: the GUSTO-I experience. Global Utilization of Strepto- kinase and TPA for Occluded Coronary Arteries. J Am Coll Car- diol. 1997;30:406-13.

20. Antoni ML, Bertini M, Atary JZ. Predictive value of total atrial conduction time estimated with tissue Doppler imaging for the development of new-onset atrial fibrillation after acute myocar- dial infarction. Am J Cardiol. 2010;106:198-203. 